
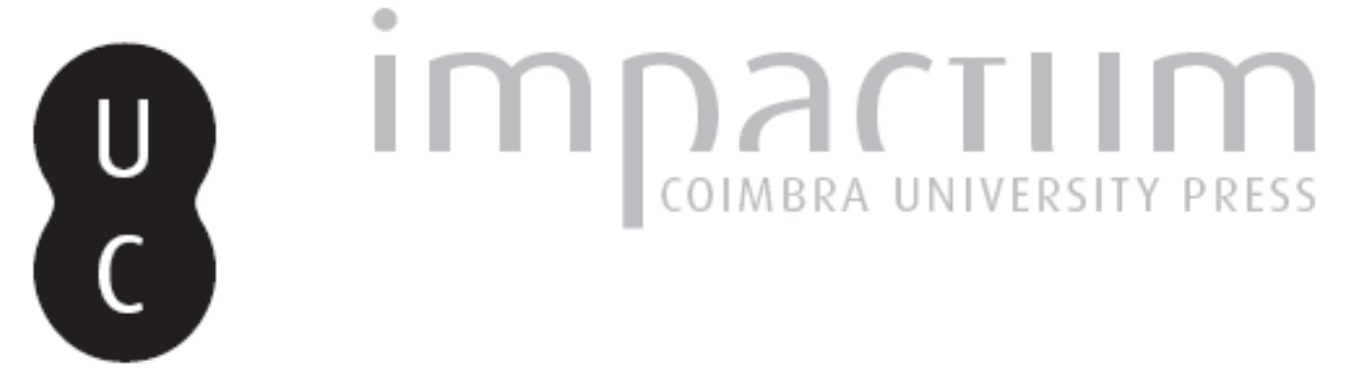

La Revolución Francesa en la prensa obrera española: (1871-1910)

Autor(es): $\quad$ Maestro, Javier

Publicado por: Imprensa da Universidade de Coimbra

URL persistente:

URI:http://hdl.handle.net/10316.2/43793

DOI:

DOI:https://doi.org/10.14195/2183-8925_10_34

Accessed : $\quad$ 26-Apr-2023 14:25:41

A navegação consulta e descarregamento dos títulos inseridos nas Bibliotecas Digitais UC Digitalis, UC Pombalina e UC Impactum, pressupõem a aceitação plena e sem reservas dos Termos e Condições de Uso destas Bibliotecas Digitais, disponíveis em https://digitalis.uc.pt/pt-pt/termos.

Conforme exposto nos referidos Termos e Condições de Uso, o descarregamento de títulos de acesso restrito requer uma licença válida de autorização devendo o utilizador aceder ao(s) documento(s) a partir de um endereço de IP da instituição detentora da supramencionada licença.

Ao utilizador é apenas permitido o descarregamento para uso pessoal, pelo que o emprego do(s) título(s) descarregado(s) para outro fim, designadamente comercial, carece de autorização do respetivo autor ou editor da obra.

Na medida em que todas as obras da UC Digitalis se encontram protegidas pelo Código do Direito de Autor e Direitos Conexos e demais legislação aplicável, toda a cópia, parcial ou total, deste documento, nos casos em que é legalmente admitida, deverá conter ou fazer-se acompanhar por este aviso. 
REVISTA DE HISTORIA DAS IDEIAS IO
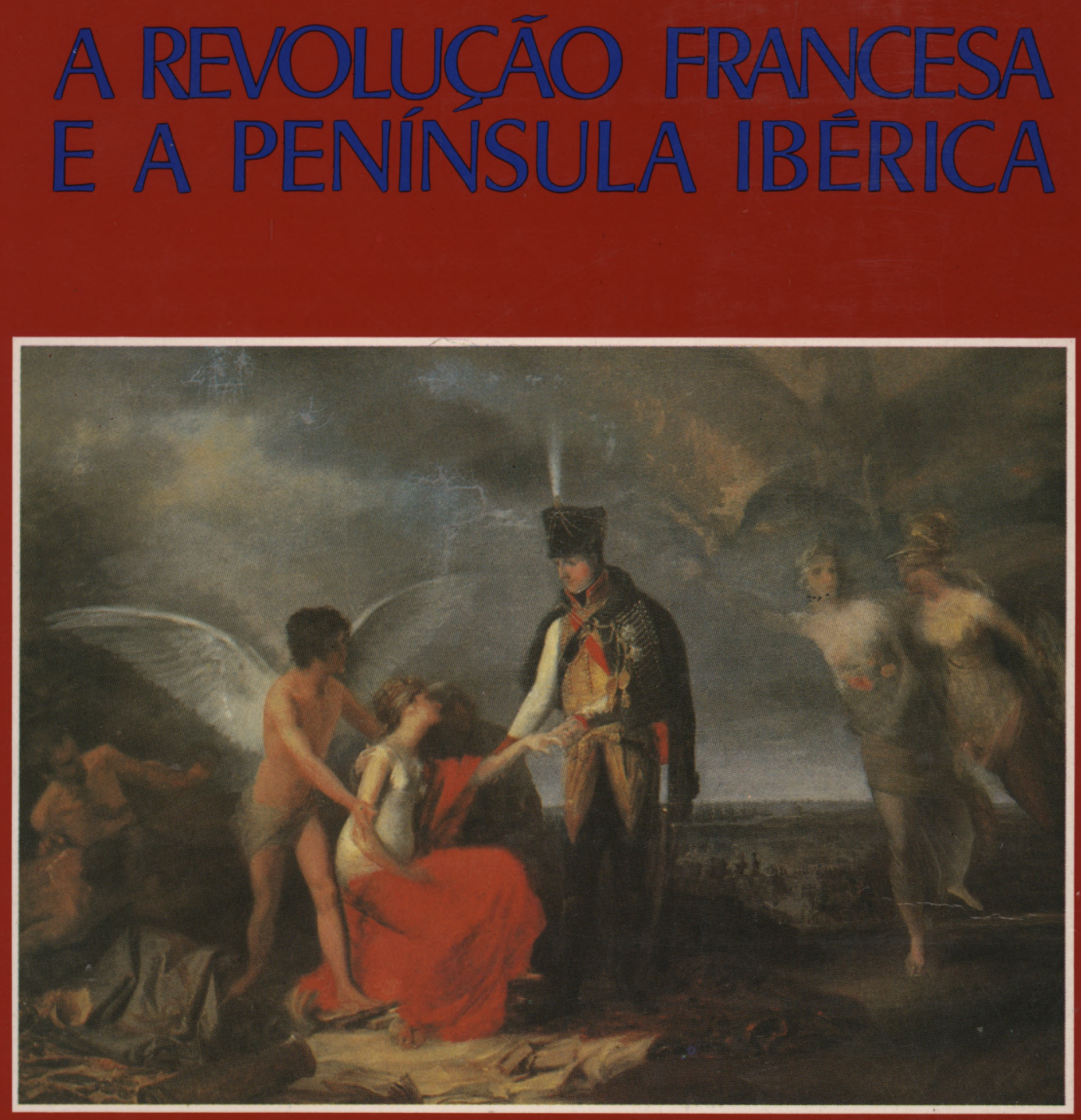

INSTITUTO DE HISTÖRIA E TEORIA DAS IDEIAS FACULDADE DE LETRAS 
JAVIER MAESTRO *

\section{LA REVOLUCIÓN FRANCESA EN LA PRENSA OBRERA ESPAÑOLA (1871-1910)}

\section{A modo de introducción}

Lelio Basso, en su obra Socialismo y revolución, suministra la siguiente consideración global sobre la influencia que ejerció la Revolución francesa en el pensamiento marxista:

«Si hiciermos un estudio acerca del influjo de la Revolución francesa sobre Marx y sus epigonos podriamos descubrir, entre los lejanos origenes de la formula de la dictadura del proletariado, la dictadura de la Convención filtrada a traves de la interpretación de Babeuf. Y entre las fuentes de inspiración del centralismo de Marx, y aun más de Lenin, encontrariamos tal vez el centralismo jacobino opuesto al federalismo girondino. La fórmula de la "revolución en permanencia». usada por Marx y por Engels en la famosa circular de 1850 , se deriva de la mencionada interpretación de la Revolución francesa como una seria de oleadas sucesivas. También la imagen que se formaron de la revolución socialista como una alianza de obreros y pequeñoburgueses. que Engels repetia todavia en su vejez, esta calcada sobre la experiencia de la París revolucionaria» (1).

La Revolución francesa, como proceso revolucionario, ha constituido explicita - o implicitamente - un modelo de referencia obligado para el movimiento obrero. A ella se remiten los analisis o las analogias historicas de los principales teóricos y/o dirigentes del movimiento obrero internacional. Los nombres de Karl Kautsky, Rosa Luxemburg, Leon Trotsky y Jean

* Universidad Complutense de Madrid.

(1) L. Basso, Socialismo y revolución, México, 1983, p. 191. 
Jaurès - por no mencionar a Carlos Marx, Federico Engels, Mijail Bakunin y Piotr Kropotkin - no agotan en absoluto a los representantes del movimiento obrero que han tenido en cuenta en sus escritos el proceso de la Revolución francesa. Pero sí constituye un elenco de nombres suficientemente ilustrativo de lo que nos proponemos señalar.

Aparte de los estudios centrados en la propia Revolución francesa, las analogías históricas han servido también de base para la caracterización de períodos concretos de la historia del siglo XX. Henri Rollin, por ejemplo, refiriéndose a situaciones históricas concretas en su obra La Revolución rusa II. Del marxismo al nacionalismo, hace la siguiente constatación.

«A las acusaciones de jacobinismo que le lanzaron los mencheviques en el Congreso de 1903, a propósito de su concepción autoritaria del partido, Lenin respondía tratándoles de girondinos, y revindicando para él y los suyos el título de "Jacobinos de la Revolución proletaria». La organización y la táctica bolchevique no son por lo demás, sino adaptaciones rusas, perfeccionadas y llevadas al limite, de la organización y de la táctica jacobinas.... (2).

Otra analogia historica es la que baraja Trotsky cuando en Estado obrero, Thermidor y bonapartismo dice que el Thermidor francés no liquidó las conquistas básicas de caracter netamente burgués de la Revolución francesa, sino que más bien apareció como un acto de reacción - pero no era una contrarrevolución - que traspasó el poder del radicalismo burgués - jacobino de la Convención a manos del sector jacobino más moderado y conservador, de la misma manera puede decirse - arguía Trotsky - que el Thermidor soviético no alteró la naturaleza de clase del Estado obrero soviético. A su modo de ver, el Thermidor soviético, como el de 1794, significaba, con arreglo a una analogía que

«....no es superficial, ni accidental, un desplazamiento del poder hacia la derecha, totalmente análogo a Thermidor, aunque los ritmos fueran más lentos y adoptaran formas más encubiertas porque la conspiración de la burocracia soviética, dirigida contra la izquierda pudo mantener durante las etapas iniciales un carácter relativamente poco sangriento - por la única razón de que se ejecutó mucho más sistemáticamente y a fondo que la improvisación del 9 Thermidor» ${ }^{(3)}$.

(2) H. Rollin, La Revolución rusa. II. Del marxismo al nacionalismo, Madrid, 1933, pp. 15-16.

(3) L. Trotsky. «El Estado obrero, Thermidor y bonapartismo», febrero de 1935, en Escritos, tomo VI, vol. 1, p. 256, Bogotá, Ed. Pluma, 1976. 
Rosa Luxemburg, por su parte, refiriéndose a la revolución rusa de 1905, establecía la siguiente comparación histórica:

\begin{abstract}
«....La revolución rusa tiene como tarea inmediata la eliminación del absolutismo y la constitución de un moderno estado de derecho parlamentario-burgués. Formalmente se trata del mismo cometido que le estaba reservado en Alemania a la Revolución de marzo y en Francia a la gran Revolución de finales del siglo XVIII.... La circunstancia decisiva es que entre aquellas revoluciones burguesas de occidente y la actual revolución burguesa del Este media todo el ciclo del desarrollo capitalista.... La burguesía no es ahora el elemento revolucionário dirigente como lo fue en las revoluciones del pasado en el Oeste, en las que las fuerzas proletarias, mezcladas con la pequeña-burguesía, servían a la burguesía como fuerza de choque» (4).
\end{abstract}

Con estos textos no pretendemos sino poner de manifiesto la frecuencia con que aparece el modelo de la Revolución francesa en el pensamiento del movimiento obrero internacional. $\mathrm{Y}$, si utilizamos estas formulaciones es para constatar también, en contraste, la indigencia de la reflexión histórica de los dirigentes del movimiento obrero español.

En efecto, ni en los escritos de los dirigentes ni en la prensa obrera española aparecen análisis históricos concretos sobre la Revolución francesa, aunque, evidentemente, esté presente su significado histórico como la revolución burguesa por antonomasia. El tratamiento de la misma es más bien de caracter circunstancial y, por regla general, se aborda de modo superficial y estereotipado, si bien habría que hacer una distinción entre los parametros de la prensa socialista y la libertaria.

Por lo demás a nadie se le escapa que otro de los factores que contribuyó para que las referencias a la Revolución francesa resultaran tan escasas en la prensa obrera española fuera atribuible al distanciamiento ideológico de la misma. No fue, sin embargo, el caso de la Comuna de Paris de 1871 a la que se dedican amplios y frecuentes espacios en la prensa española. La referencia es casi obligada cada mes de marzo con motivo de celebrar el aniversario de la misma.

(4) R. Luxemburg, Escritos Políticos, Barcelona, Ed. Grijalbo, 1977, pp. 206-208. 


\section{La Revolución francesa en la prensa anarquista}

El arraigo que alcanzó el anarquismo en los albores del movimiento obrero español es, como comunmente se sostiene, un fenómeno asociado a la propia debilidad politica y organizativa del movimiento obrero, a su vez directamente relacionada con el estado de incipiente industrialización y escaso desarrollo del capitalismo hispano $\left(^{5}\right)$. En efecto, semejante debilidad se manifestaba paradójicamente a traves de un bajo nivel de conciencia de clase a la vez que de un elevado grado de combatividad. Esta ultima característica se debió, entre otras razones, a las avanzadas experiencias políticas que conoció el embrionario movimiento obrero español durante el periodo 1868-1874 - una especie de 1848 retardado. A todo ello quizás se deba la preponderancia del subjetivismo revolucionario y la impronta ético-sentimental del ideario ácrata.

En la prensa anarquista y anarco-sindicalista la idea de progreso constituye una de las constantes de su ideario, de forma tal, que a diferencia de la doctrina socialista, éstos aparecen como los continuadores de la revolución burguesa y de la ideología liberal. No es, por consiguiente, sorprendente que su visión de la historia coincida básicamente con la que sustentaban los liberales españoles más avanzados de la época: los republicano-federales. Los anarquistas españoles no sentían por ello - como observa Alvarez Junco - «ninguna necesidad de escribir una historia propiamente libertaria de los acontecimientos anteriores al siglo XX, sino - que en la Escuela Moderna, por ejemplo, se utiliza la historial del federal N. Estevanez... La continuidad entre la ideologia liberal y el ideario ácrata, a traves de una idea linear como el «progreso» o la «libertad», sería perfecta si no se hubiera roto, según explica Bakunin, por la «traición» de la burguesía a sus ideales progresivos. La burguesía «no ha sabido ser igualitaria en el reparto de los beneficios» de su revolución, y «a esto viene el socialismo: a subsanar las deficiencias de la democracia» $\left({ }^{6}\right)$.

Anselmo Lorenzo, principal difusor de las ideas libertarias en España, llegó incluso a afirmar que «el problema po-

(5) Sobre este particular véase lo que señalo al respecto en mi tesis doctoral "Trotsky y los origenes de la izquierda comunista española en el contexto histórico de la polémica reforma o revolución", Universidad Complutense, 1986, pp. 79 y ss.

(6) J. Alvarez Junco, La ideología política del anarquismo español (1868-1910), Madrid, 1976, pp. 106-107. 
litico del mundo quedó resuelto en 1789 en Francia con su Gran Revolución».

De cómo la burguesía «traicionó» su ideal de progreso puede leerse lo que sigue en la revista Acracia de junio de 1887:

«....en la siempre citada revolución francesa, hubo un elemento, el más radical, al parecer, que concluyó por sacrificar con sus extravíos aquella grande obra. Al mismo tiempo otro elemento opuesto al primero fue acusado entonces de reaccionario y pagó en el cadalso las culpas de sus propios acusadores.

Robespierre y Danton, los dos genios de aquel movimiento grandioso, representaban la primera y segunda tendencia respectivamente Danton y su partido constituían el verdadero nervio de la revolución por sus aspiraciones federalistas y descentralizadoras; Robespierre y los suyos, nacidos también al calor de la revolución, extraviaron el principio, $y$ en nombre de la salud del pueblo sacrificaron revolución y pueblo, justicia y libertad.

Sobre las ruinas de este dualismo de fuerzas surgió amenazadora la reacción. ¿Sabeís la forma? ¿Conoceís el agente?

La forma tomó cuerpo con el decreto sobre el culto del Ser Supremo; el agente fue el ídolo revolucionario, fue Robespierre, de quien dicen Proudhon y Bakounine que era el profeta de la divinidad.

Y aquella Republica que nació al grito unánime de libertad e igualdad, aquella subversión formidable de los oprimidos, quedó pronto reducida, convertida al privilegio, a la autoridad, adquiriendo proporciones tan odiosas por lo tiránicas, como lo habían sido las del poder que acababa de derrumbar: el despotismo de Luis XVI.

Todavía la influencia de aquella reacción se conoce en nuestros tiempos con el dictado de jacobinismo, y es comun a todos los partidos democráticos, a las escuelas socialistas y a cuantas se precian de reformadores o revolucionarios....» (7).

Estos parrafos hablan de por sí. En este caso, como en tantos otros, el objetivo no era desde luego conocer con mayor rigor la Revolución francesa, sino utilizar de forma partidista elementos de la misma para fines de lucha ideológica contra el «centralismo» y «autoritarismo» de los marxistas. Unos años más tarde, el proceso revolucionario francés suministró una linea argumental propicia para polemizar con los republicanos. Así, en 1907, dos años antes de que se configurara la conjunción republicano-socialista, el diario Tierra y Libertad, del 8 de agosto, y bajo el titulo «¡Oh republicanos!», explicaba

(7) Acracia, n. 18 , junio de 1887, Barcelona. 
una vez más desde supuestos éticos los vicios de origen de la forma de Estado republicana:

"Cuando los trabajadores franceses habian creído que con el advenimiento de la Republica se acabaron los atropellos e injusticias que con ellos cometía la nobleza, véanse hoy que tienen que agruparse en sus sindicatos para hacer frente a la nueva burguesía democrática, quien en nombre de la libertad, la igualdad y fraternidad les sigue sacando el iugo y atropellándolos del mismo modo que lo hacía antes la otra.

Pues bien, los que sirvieron de escala para que subieran al poder los nuevos amos, tienen que hacer hoy lo mismo que hicieron antes, es decir, derribar a los que un día por su elocuencia supieron engañar al pueblo....».

Un mayor rigor histórico parece alumbrarse cuando, en el mismo diario anarquista, aparece el 10 de junio de $1909-$ un primer articulo sobre la «Gran Revolución» de Piotr Kropotkin. Pero, que sepamos, sólo se llegó a publicar ese único articulo de lo que debía ser una larga serie. Tal interrupción se debió, con toda seguridad, a los acontecimientos de la «Semana Trágica» que demandaban todo menos articulos de carácter histórico. No obstante, y sin que puede precisarse la fecha exacta, la obra de Kropotkin sobre la Revolución francesa se publicó en Barcelona hacia 1910. La traducción corrió a cargo de Anselmo Lorenzo, pero, curiosamente, sin prólogo ni comentario alguno del mismo.

Con anterioridad, entre 1904 y 1905, la revista quincenal de Ciencia, Sociología, Literatura y Arte, Natura, introdujo sistemáticamente artículos de Kropotkin sobre la Revolución francesa, aunque en versión abreviada por el propio autor. Fueron concretamente cuatro articulos relacionados con la abolición de los Derechos feudales, tres artículos sobre los anarquistas y la Gran Revolución, y cinco artículos sobre la reacción en 1790 y 1791 .

\section{La Revolución francesa y la prensa socialista}

El primer órgano de expresión del socialismo español, Emancipación, aparecido en 1871 y fuertemente lastrado por el bagaje ideológico anti-autoritario de la Federación Regional Española de la AIT, al igual que el nucleo político socialista que lo impulsaba - La Nueva Federación Madrileña, embrión del PSOE -, inició su andadura política polemizando con la burguesía avanzada, su rival politico más inmediato. Así, el 2 de octubre de 1871 se propuso hacer las siguientes puntua- 
lizaciones sobre el concepto de Republica democrático-social que la Federación Regional Española de la AIT había recogido en sus acuerdos de Valencia de septiembre de 1871:

«La idea moderna de la república democrática surgió en Francia del gran movimiento revolucionario de 1793, con los sublimes principios de libertad, igualdad y fraternidad. Como todas las ideas que entrañan la verdad y la justicia, nació potente y avasalladora y destruyó de un soplo todos los obstáculos que se oponían a sua realización.

Pero una clase, la clase media, que había sido la iniciadora del movimiento, no tardió en apoderarse de él. Negó inmediatamente las consecuencias lógicas de los principios que ella había proclamado, y desde entonces, la revolvción quedó ahogada, y república y democracia solo fueron palabras vanas y engañosas.

La clase media, al apoderarse de los bienes de la aristocracia y del clero, se puso en lugar de estas dos clases privilegiadas, declarando inviolable la propiedad misma que ella había secuestrado e inmutable la antigua organización del trabajo. fundada en la explotación y en la injusticia. Hizo más: - para poner en armonia aparente los grandes principios de la revolución y sus bastardos intereses de clase, falseó la ciencia. organizó la corrupción e introdujo por doquiera la confusión y el escepticismo.... Así, pues, la propiedad individual y el Estado autoritario han sido hasta ahora la base comun de todos los partidos políticos, conservadores, reaccionarios, moderados, progresistas demócratas y republicanos unitarios y federales».

El mismo semanario, con fecha 28 de enero de 1872, vuelve a hacer alusión a la Revolución francesa, en esta ocasión para señalar que el proceso revolucionario francés privó a las clases trabajadoras del derecho de asociación, es decir, del derecho de defender sus condiciones de vida, por lo que concluye que:

"La fórmula trinitaria, Libertad, Igualdad y Fraternidad, quiere decir: todos los hombres deben ser iguales ante la esplotación capitalista; es preciso que la esplotación sea libre, pueda llevarse hasta lo infinito; es preciso que pueda esplotarse fraternalmente a todos los hombres. sin distinción de raza ni de color».

Más tarde, el 11 de mayo de 1872, el semanario inserta un articulo sobre «El partido proletario en Francia», con el fin de trazer los orígenes de la desvinculación obrera de la burguesia. Dice al respecto:

«.....No tardó en empeñarse la lucha entre el pueblo representado por la Commune de París y la Asamblea de los diputados. Dominaban en la Asamblea los girondinos, especie de federales a la manera de los que dirigen en España 


\section{Revista de História das Ideias}

al partido de este nombre, pero más animosos, que querían transformar la Francia en provincias como las Vascongadas, donde la burguesía debía reemplazar a los señores feudales que acababan de perder sus privilegios. A los girondinos sucedió Robespierre, jesuita perfecto, que engañaba a la clase obrera, sirviendo a la burguesía a la vez que aparentaba un inmenso amor por las virtudes del pueblo. En la Commune estaban los hombres procedentes de todos los ámbitos de la Francia y de los demas paises.... La Commune de 1793, lo mismo que la de 1871, fue vencida, y Robespierre envió al cadalso a Hébert....».

Emancipación fija por tanto la ruptura en terminos de clase, por cuanto los trabajadores fueron los grandes - derrotados a lo largo del proceso revolucionario francés, puesto que «después de la muerte de Babeuf todo concluyó para el pueblo», aunque «el infatigable Buonarroti, descendiente de Miguel Angel y amigo de Babeuf, a quien salvó, propago luego la idea comunista por toda Europa».

Tras la efímera existencia de la corriente filo-marxista española, el socialismo no daría señales de vida hasta su fundación en 1879 por una veintena de trabajadores de la madrileña - Asociación General del Arte de Imprimir. Pero, como diría Pablo Iglesias, el fundador, el socialismo español no daría verdaderas señales de vida hasta 1886. En ese año aparece el semanario $E l$ Socialista que, desde entonces, difundió, como el PSOE, una visión distorsionada del marxismo, basada en el esquematismo guesdista, es decir reduciendo el marxismo a una serie de «verdades generales» sometidas a un rudo determinismo económico salpicado de - obrerismo lastimero. Hasta principios de siglo, la doctrina pabloiglesista propugnaba incansablemente una línea de «clase contra clase», una «guerra constante y ruda» contra el republicanismo, politica que quedó vertebrada por el principio de independencia de clase, pero enfrentada al subjetivismo revolucionario de los anarquistas españoles.

Con arreglo a estas coordenadas, la reflexión histórica y la necesidad de analizar la realidad española resultaban poco menos que supérfluas. Tanto es así que el socialismo español no aportó ni aportaría ningún análisis serio sobre el desarrollo de las fuerzas productivas en España y las concomitantes relaciones sociales que se desprendian de ello. El socialismo español se conformaba con señalar que, con arreglo a leyes históricas inexorables, estaba muy próximo el fin del sistema capitalista; después, hacia 1900, el sometimiento a la disciplina de la II Internacional, la creciente sensibilidad de los gobiernos por la denominada «cuestión social» así como los escasos avances organizativos y electorales del socialismo español, propició un acer- 


\section{La Prensa Obrera Española (1871-1910)}

camiento de éste al republicanismo y también a sucesivas revisiones programáticas, todo ello orientado a consolidar el objetivo de priorizar la revolución politica frente a la revolución social.

Sirvan estas apreciaciones para entender el prisma a través del cual el socialismo español interpretó a partir de entonces el proceso revolucionario francés.

Así, el 4 de mayo de 1888, El Socialista publicaba el primero de una serie de cuatro artículos firmados por Edouard Bernstein bajo el título de «Consideraciones sobre la Revolución francesa». Bernstein confesaba que, al traducir la obra de Deville sobre la Revolución francesa, había llegado a la conclusión de que los lectores alemanes, a diferencia de los franceses, no estaban lo suficientemente familiarizados con el tema, una circunstancia que le movió a radactar un apéndice a la versión alemana. Suponemos por ello que El Socialista perseguía el mismo fin al incorporar los artículos de Bernstein. Nos interesa sobre todo reproducir lo que se decía en el primero de esos artículos. Entre otras cosas Bernstein afirmaba que:

«Hasta la supresión del partido hebertista - verdadera representación del pueblo de París - por Robespierre, la Revolución habia seguido una marcha ascendente. Es verdad que la dictadura revolucionaria de Robespierre y el Comité de Salvación pública duró todavia algunos meses después de la caida de los hebertistas pero no tardó en envidenciarse que la amputación de los ultrarrevolucionarios tan calumniados sólo había servido para dar nuevos alientos a los adversarios de la democracia. El 9 de thermidor del año II (27 de julio de 1794) tuvo lugar la caída de Robespierre, y poco después, el mes de noviembre del mismo año, la supresión del club de los jacobinos.

A contar desde esta época, la contrarrevolución no tuvo freno. En lugar del 'populacho' de los arrabales, es decir, de la clase trabajadora, dominó desde entonces la influencia de los 'hombres honrados'».

Estos parrafos condensan cómo se entendieron las fases fundamentales del proceso revolucionario francés.

Los articulos de Bernstein precedieron a aquellos que El Socialista publicaría con ocasión de conmemorarse el primer centenario de la Revolución francesa. El primer artículo de esta índole se publicó el 11 de enero de 1889 con el significativo titulo de «1789-1889». El objetivo era plantear un distanciamiento de una conmemoración que protagoniza la burguesía. $Y$ lo expone de la siguiente manera:

"La clase dominante, los que imponen sus leyes. su voluntad y su capricho a millones y millones de seres, propónense 
celebrar este año el centenario de su domino.... si las fuerzas socialistas revolucionarias no dieran muestras de hallarse pronto en situación de demoler las instituciones burguesas y reemplazarlas con otras basadas en la igualdad social, y en la solidaridad humana, la celebración de la referida fiesta burguesa debería entristecernos y desesperarnos....»

A continuación el mismo articulo suministra una nota reconfortante al postular que:

"No hemos pecado de visionarios ni de exagerados los socialistas al afirmar que el cadáver de la burguesía será arrojado a la fosa antes de que alboree el siglo XX».

El optimismo revolucionario estaba vinculado a la convocatoria en Paris de los representantes del socialismo internacional, que, como se sabe, resultaría en la fundación de la II Internacional Socialista. El semanario socialista dice al respecto:

«Y icosa rara! en ese mismo Paris que va a servir de punto de cita y de lugar de algazara y de bullicio a los mayores tiranos de la tierra, á los más infames explotadores y á los bandidos más cobardes, van a reunirse también los representantes del proletariado del mundo para jurar solemnemente concluir con la clase parasita y adoptar las medidas más apropiadas á la realización de su propósito.... Puede, por tanto, la burguesía lanzar un grito de júbilo al ver que su dominación ha cumplido un siglo; pero tendrá que lanzar también otro de espanto, que acelerará su muerte, al contemplar el inmenso ejército de asalariados que se levantará ante ella para derrocar su poderío y extirpar de raiz la explotación del hombre por el hombre».

El 24 de mayo de 1889 El Socialista recoge un artículo sobre «El centenario de la Revolución francesa» que contiene unos argumentos cuando menos sorprendentes, rayanos en el reaccionarismo, sobre el valor histórico de la Revolución francesa, pues tras señalar que:

"Si se nos perguntara lo que opinamos sobre la necesidad de esta Revolución, que empezó por una vulgar subasta de prerrogativas y terminó dando el triunfo al mejor postor.... contestaríamos que desde el punto de vista de la evolución sociológica, el movimiento nos parece indudablemente necesario como fase transitoria y la situación creada de sus resultas justificada por la ley histórica que exige que de dos clases en lucha, una de ellas desaparezca para dejar libre el campo al combate supremo por la desaparición completa de las clases.... 


\section{La Prensa Obrera Española (1871-1910)}

introduce una nota nostálgica y reaccionaria al plantear que:

«....si se desea saber nuestra predilección entre el régimen derrotado en 1789 y el que fundaron los revolucionarios de la Convención y su continuador el primer Bonaparte, no vacilamos en declarar que, como obreros y aun como demócratas, preferiríamos mil veces vivir, si fuera posible, en una sociedad en que la propiedad no habia sido declarada todavía de derecho divino, inviolable y en los que la detentaban hacian un uso de ella mucho más elevado, más generoso que los insaciables usureros que hoy la poseen; en que el trabajo, que no era todavía libre, ó en otros términos, que no se había abierto aún a la 'libre explotación de la burguesía', se hallaba al abrigo de las oscilaciones creadas por la especulación y garantizado, hasta cierto punto contra la rapacidad de los patronos, $y$, por último. en que las relaciones sociales, merced a la buena educación, a los nobles sentimientos de la clase poseyente no revestía ese carácter de despego, de egoísmo feroz. de crueldad inhumana que impera en nuestra sociedad de groseros advenedizos que ha tomado por divisa: ¡Cada cual para sí, y desgraciado del que no posee!».

El Socialista, al recordar la fecha del 14 de julio, vuelve a hacer una exposición argumental semejante a las que hemos reproducido hasta ahora, puesto que, después de apuntar que «el triunfo de la burguesia sobre la nobleza y la teocracia señala un progreso en la evolución humana», insiste en el hecho de que:

«....Las fechas que la clase trabajadora consciente debe conmemorar y enaltecer, son aquellas en que los suyos, obrando con personalidad propia, procediendo como tal clase, hayan peleado por sus intereses y derramado su sangre por la causa que ha de emanciparlos.

Las Bastillas cuyo derribo han de librar al pueblo de su esclavitud politica. económica y social están en pie todavía, y lo que los desheredados deben hacer.... es redoblar sus esfuerzos y su actividad para asaltarlos cuanto antes y concluir con ellas" ( $\left.{ }^{8}\right)$.

Apenas encontramos referencias a la Revolución francesa durante el siguiente decenio. En cambio, en 1901, La Nueva Era, insertó un artículo de Emilio Vandervelde, «El siglo de los obreros», donde se hacía el siguiente pronóstico:

"El siglo XIX comenzó con «La Marsellesa» y acaba con «La Internacional....» Era el dia siguiente del 18 Brumario. La República francesa acababa de morir. Graco Babeuf y sus

(8) El Socialista, del 19 de julio de 1889. 


\section{Revista de História das Ideias}

amigos de la Conjuración de los Iguales, guillotinados en 1796, parecían haber llevado su hijo - el socialismo -, a la fosa común de las ideas revolucionarias. La burguesía, desgarrando la Declaración de los derechos del hombre, se contentaba con el Código Civil; el sufragio universal, que engendró la Convención, era abolido el $10^{\circ}$ vendimiario del año IV.... El absolutismo imperaba sin trabas en todos los países. El tronar de los cañones de Marengo cubría los clamores de la libertad» $\left({ }^{(}\right)$.

Hemos tratado de encontrar alguna referencia al impacto que ejercio la Revolución francesa en la peninsula ibérica. No aparecen apenas referencias a ese capitulo de la historia contemporánea de España. En mayo de 1908, al celebrarse en el país el primer centenario del inicio de la guerra de Independencia, El Socialista inserta un pequeño articulo firmado por Francisco Nuñez. En el mismo se vuelven a barajar argumentos similares a los que esgrimió el semanario socialista con ocasión del centenario de la Revolución francesa. Entre otras cosas afirmaba que:

«Hoy es el dia que los trabajadores consagran á su objetivo, á su ideal bienhechor, á la consecución de un derecho [se refiere al $1 .^{\circ}$ de mayo]); mañana es el en que los patriotas, los amantes de nuestras pasadas glorias, los que de la guerra hacen un negocio, la burguesía. en fin, conmemoran actos guerreros, sangrientos e inhumanos. El dia de hoy es una aspiración; el de mañana [la celebración del 2 de mayo de 1808 ] es un recuerdo. Nosotros celebramos la fiesta del bien, la de la inteligencia y del amor entre todos los hombres que producen, que aportan algo útil a la vida: ellos verifican la del odio entre dos pueblos, la de actos abominables que costaron la vida a infinidad de seres humanos. Hoy se reunen los trabaiadores de todo el mundo que, mirando al provenir, solicitan mejoras a las cuales tienen perfecto derecho: mañana se congregan los individuos de un pueblo que fijan su vista en un pasado devastador. El 1. de mayo es una fiesta positiva: el 2 de mayo lo es negativa.

Dicen que desde este año a la celebración de la invasión francesa, y con motivo de la cordialidad de relaciones que actualmente existen entre los Gobiernos de Francia y España, dejara de conmemorarse ya la fiesta del 2 de mayo, a fin de no molestar al vencido en $1808 \ldots . . .(10)$.

Como se desprende de los parrafos que hemos reproducido, la lógica maniquea seguía imperando en las reflexiones históricas.

(9) La Nueva Era, Madrid, junio de 1901.

(10) El Socialista, 3 de mayo de 1908. 
$\mathrm{Y}$, como ya apuntamos, tal lógica se abandona gradualmente a partir de 1909 una vez creada la conjunción republicano-socialista. El objetivo de realizar una revolución politica en España con las fuerzas progresistas repercute en una reevaluación de la posibilidad de transformar la sociedad mediante sucesivas reformas.

Sin embargo, la reorientación estratégica no va acompañada de mayor perspicacia historica. Muy al contrario. La indigencia teórica se refleja también en la pobreza de los análisis historicos. 